\title{
\%
}

\section{ACUERDO DE PARTENARIADO ECONÓMICO UE-JAPÓN}

El 1 de febrero de 2019 entró en vigor el Acuerdo de Libre Comercio entre la Unión Europea y Japón, también conocido como Acuerdo de Asociación Económica, o EPA (Economic Partnership Agreement, por sus siglas en inglés). La UE y Japón suman alrededor de la cuarta parte del PIB mundial. El EPA constituye un acuerdo amplio, ambicioso y profundo, que va más allá de las cuestiones de acceso al mercado y que facilitará e impulsará los intercambios comerciales y de inversión entre las dos regiones, con el fin último de contribuir positivamente al crecimiento y a la generación de empleo.

Palabras clave: comercio, inversión, sector agroalimentario, automoción, contratación pública, propiedad intelectual.

Clasificación JEL: F14, H57, O34.

\section{Introducción}

Las negociaciones relativas a un acuerdo comercial entre la UE y Japón, ambicioso, amplio y profundo, comenzaron de forma oficial en marzo de 2013, tras obtenerse el visto bueno del Consejo de Ministros de la UE en su configuración de Asuntos Exteriores y Comercio. El mandato de negociación se basó en un Estudio de Impacto de la Comisión Europea, que recomendaba a las partes negociar un acuerdo de libre comercio amplio, profundo y ambicioso.

Tras la realización de un total de 19 rondas de negociación, enmarcadas en la celebración

\footnotetext{
* Este artículo ha sido elaborado por Rocío Frutos Ibor, Ángel Abelleira y Juan Carrero Roig.

Versión de agosto de 2019.

DOI: https:/doi.org/10.32796/bice.2019.3115.6902
}

de sendas Cumbres UE-Japón, las partes alcanzaron un acuerdo de principio en julio de 2017 y las negociaciones finalizaron en diciembre de 2017.

Posteriormente, el 17 de julio de 2018, Japón y la UE firmaron en Tokio el acuerdo político, en una reunión celebrada entre los presidentes de la Comisión y el Consejo Europeo, JeanClaude Juncker y Donald Tusk, y el primer ministro de Japón, Shinzo Abe.

Una vez firmado el acuerdo político, se requería como paso previo a la entrada en vigor la conclusión, aprobación y ratificación interna por ambas partes. Así, en diciembre de 2018, la Dieta (Parlamento japonés) y el Consejo de la UE ratificaron el acuerdo, que entró en vigor el pasado 1 de febrero de 2019.

En el caso de la UE, la entrada en vigor del EPA generará grandes oportunidades para $\triangleright$ 
sus Estados miembros y sus empresas, aumentando el acceso a un mercado tradicionalmente cerrado a los agentes extranjeros.

El objetivo principal del ALC UE-Japón consiste en la creación de un entorno en igualdad de condiciones entre las economías de la UE y de Japón ${ }^{1}$, fomentando así el comercio, la inversión y la cooperación económica a nivel bilateral. Dado que Japón imponía elevados aranceles sobre los productos europeos, la eliminación de barreras arancelarias ha constituido una prioridad en las negociaciones de la UE con Japón.

Sin embargo, ha sido más importante aún la eliminación de barreras no arancelarias. La UE afrontaba en el mercado japonés una serie de obstáculos técnicos, como el uso de estándares distintos a los internacionales. Para la UE, resultaba clave que Japón adecuara sus normas a las internacionales, facilitando de esta manera las exportaciones de las empresas de la UE a Japón, que de otro modo se veían obligadas a crear líneas de producción exclusivas para atender al mercado japonés con el consiguiente aumento de costes. En este sentido, la negociación ha permitido la resolución de numerosas barreras existentes, incluso antes de la entrada en vigor del acuerdo.

Finalmente, a través de la negociación del acuerdo, la UE y Japón buscaban enviar una señal clara de que dos de las mayores economías del mundo rechazan de pleno la falta de respeto al level playing field y las presiones proteccionistas, defendiendo de manera firme el multilateralismo, y abriéndose a la actividad empresarial y al comercio sobre la base de unas normas justas y estrictas.

Se busca crear un level playing field o un terreno de juego equivalente para los actores de ambas partes, generando un entorno igualitario de actuación para los mismos.

\section{Relaciones bilaterales UE-Japón y España-Japón}

\subsection{Relaciones UE-Japón}

El acuerdo se enmarca dentro de un contexto de relaciones comerciales intensas de la Unión Europea y Japón. Este país es el sexto socio comercial más importante para la UE a escala mundial, y es además su segundo mayor socio comercial en la región de Asia, solo por detrás de China. Japón es un socio fiable para la UE, con estándares de productos y de protección de los consumidores muy elevados, y que se preocupa asimismo de aspectos medioambientales y laborales ${ }^{2}$, relevantes para la UE.

La UE exporta anualmente a Japón más de 58.000 millones de euros ${ }^{3}$ en bienes, destacando sectores como el de vehículos a motor, maquinaria, productos farmacéuticos, instrumentos ópticos y médicos y maquinaria eléctri$\mathrm{ca}$, entre otros. A dicho volumen se sumarían los más de 28.000 millones de euros exportados anualmente en servicios.

En lo que se refiere al empleo y número de empresas que exportan de forma regular a Japón desde la UE, cabe señalar que hay más de 600.000 puestos de trabajo vinculados a las exportaciones de la UE a Japón. Además, casi 74.000 empresas comunitarias exportan de forma regular a Japón, siendo alrededor de un $78 \%$ de ellas pequeñas y medianas empresas.

\footnotetext{
2 Destaca en este caso la ratificación de las convenciones fundamentales de la Organización Internacional del Trabajo (OIT).

3 Datos de Eurostat. Dicha cifra refleja un promedio de las exportaciones de los últimos años de la UE a Japón. Para mayor información, consultar el siguiente enlace: $h$ ttps://webgate.ec.europa.eu/ isdb_results/factsheets/country/details_japan_en.pdf Puede consultarse también: http://ec.europa.eu/trade/policy/in-focus/eu-japan-economicpartnership-agreement/
} 


\subsection{Relaciones España-Japón ${ }^{4}$}

España mantiene importantes vínculos comerciales y económicos con Japón. El país asiático ocupa el noveno puesto como destino extracomunitario de las exportaciones españolas de mercancías con una suma que ascendió a 2.527 millones de euros ${ }^{5}$ en 2018 , doblando el valor de las mismas en los últimos años (1.213 millones de euros en 2009). Desde la irrupción de la crisis, España ha estrechado sus lazos comerciales con Japón, tal como demuestra el fuerte incremento experimentado en nuestra tasa de cobertura ${ }^{6}$, que ha pasado del $20 \%$ en 2004 al $61,1 \%$ en 2018.

Las principales partidas de mercancías exportadas desde España a Japón se concentran en las siguientes (datos de 2018): carne y despojos comestibles (17,29\%); productos farmacéuticos $(14,84 \%)$; vehículos automóviles y tractores $(13,14 \%)$; grasas, aceite animal o vegetal $(5,55 \%)$; minerales, escorias y cenizas (4,68\%); prendas de vestir no de punto $(4,48 \%)$; pescados, crustáceos y moluscos $(3,68 \%)$; bebidas de todo tipo excepto zumos $(3,67 \%)$; productos químicos orgánicos $(3,43 \%)$ y prendas de vestir de punto $(2,46 \%)$.

Los productos que más crecieron en el año 2018, comparado con el mismo periodo del año anterior, fueron los pescados, crustáceos y moluscos $(44,07 \%)$ y los minerales, escorias y cenizas $(22,28 \%)$, mientras que disminuyeron significativamente los vehículos automóviles y tractores $(-8,74 \%)$ y las grasas, aceite animal o vegetal $(-8,06 \%)$.

\footnotetext{
4 Más datos disponibles en el Anexo I.

5 Datos obtenidos de la base de datos DataComex de la Secretaría de Estado de Comercio.

6 Representa el porcentaje de importaciones que pueden pagarse con las exportaciones realizadas durante un mismo periodo de tiempo, al relacionar ambas magnitudes $(\mathrm{TC}=\mathrm{EXP} / \mathrm{IMP})$.
}

Las importaciones de bienes españolas procedentes de Japón alcanzaron los $4.132 \mathrm{mi}-$ llones de euros durante el año 2018. Las principales importaciones se registraron en el sector de vehículos automóviles y tractores (49,7\%); máquinas y aparatos mecánicos (18,6\%); aparatos y materiales eléctricos $(9,9 \%)$; aparatos ópticos, de medida y medición $(5,5 \%)$ y productos químicos orgánicos (2,7\%).

Respecto a las empresas españolas que exportan regularmente a Japón, su número asciende a 9.084 en el año 2018, incrementándose frente a las registradas en 2017.

Asimismo, cabe resaltar que nuestro comercio de servicios con Japón ${ }^{7}$ arroja un saldo positivo con una tasa de cobertura del $323,4 \%$ en 2018. Las exportaciones de servicios de España hacia Japón alcanzaron los $1.161 \mathrm{mi}-$ llones de euros en 2018, siendo los principales sectores de exportación el sector de servicios empresariales, el turismo, los servicios gubernamentales y los servicios de transporte. En la importación, los sectores destacados vuelven a ser servicios empresariales, transporte y turismo.

En materia de inversiones ${ }^{8}$, España es el decimosegundo destino para Japón, con un stock en 2016 de 5.702,2 millones de euros (un $36 \%$ más que en 2015), lo que supone un $1,17 \%$ del total. Aproximadamente, el $55 \%$ se concentra en cuatro sectores: comercio al por mayor excepto vehículos de motor, fabricación de vehículos de motor, fabricación de bebidas e industria química. Otros sectores relevantes son los de fabricación de productos metálicos, sector informático y fabricación de productos de caucho.

\footnotetext{
7 Fuente: Banco de España.

8 Fuente: Registro de Inversiones de la Secretaría de Estado de Comercio. Stock de inversión no ETVE.
} 


\section{Contenido del acuerdo}

De estos datos se desprende la importancia de haber alcanzado un acuerdo amplio y profundo, cuyo alcance va más allá de las mejoras en el acceso al mercado por las partes.

Hay que recordar que ambas partes se comprometen a reducir de forma importante los aranceles impuestos a la importación en sus respectivos mercados. Así, la UE elimina un $99 \%$ de los aranceles impuestos antes de la firma del acuerdo a los productos japoneses, mientras que Japón elimina un $97 \%$, al que hay que sumar las concesiones realizadas en productos sensibles, a través de la fijación de contingentes arancelarios.

La mayoría de los derechos de aduana $(91 \%)$ se eliminan por parte de Japón con la entrada en vigor del acuerdo para muchos productos de interés, entre los que se incluyen automóviles, químicos, textiles y confección, metales, cerámica y vidrio, plásticos y vinos. El resto desaparecerá gradualmente en función de la partida estadística, con un periodo de desmantelamiento máximo de quince años.

La eliminación de derechos aduaneros por parte de Japón podrá suponer para las empresas de la UE un ahorro de 1.000 millones de euros al año (cuando se alcance la plena implantación del acuerdo y el aprovechamiento de las preferencias arancelarias), con un aumento anual previsto de las exportaciones de más del $13 \%$ (unos 13.000 millones de euros anuales). Además, con el objetivo de aprovechar plenamente las ventajas arancelarias que ofrece el acuerdo, se ha logrado que las autoridades de Japón reconozcan el procedimiento de declaración de origen que la UE mantiene en otros acuerdos ${ }^{9}$, basado en

9 Sistema REX (https://www.agenciatributaria.gob.es/AEAT.sede/ tramitacion/DC47.shtm/): el sistema basado en el conocimiento del importador determina que es el importador el que está obligado a la autocertificación, en lugar de la práctica habitual de conocimiento del importador que establece Japón para las importaciones de terceros países.

Como se ha señalado anteriormente, además de eliminar las principales barreras arancelarias, Japón se compromete a eliminar y reducir barreras de tipo no arancelario, uno de los principales obstáculos que encuentran las empresas españolas en la exportación de bienes a Japón.

Asimismo, el acuerdo incluye disciplinas transversales que cubren todos los aspectos comerciales. La liberalización de los mercados de bienes va acompañada de una mejora en el acceso recíproco al sector de contratación pública, además de mejorar en general el clima de negocios entre los Estados miembros y Japón.

También se ha alcanzado un acuerdo ambicioso en materia de inclusión de pequeñas y medianas empresas, propiedad intelectual, servicios e inversiones, etcétera. Es destacable la incorporación de un capítulo extenso en desarrollo sostenible (en materia laboral y medioambiental) cuestión de gran relevancia para España, que aboga por la implementación de una política comercial sostenible e inclusiva.

Todas estas cuestiones se desarrollan a continuación con más detalle, analizando los principales capítulos que componen el acuerdo.

\subsection{Sector agroalimentario}

Entrando más en profundidad en el contenido del acuerdo, cabe destacar su importancia para las exportaciones de productos agroalimentarios. Japón representa un mercado de $\triangleright$

demostrar el origen de la mercancía. En la práctica esto supone que el importador puede solicitar al exportador información sensible para la empresa. 
alto valor para los productores y exportadores europeos del sector. El valor de las exportaciones europeas en 2018 para los productos agroalimentarios superó los 5.700 millones de euros ${ }^{10}$, por lo que Japón constituye el cuarto mercado más importante para productos europeos.

Con el tiempo, y tras la plena implantación del acuerdo, el $85 \%$ de los productos agrarios europeos (en líneas arancelarias) podrán entrar en el mercado japonés sin aranceles.

Por lo tanto, desaparece la mayor parte de los derechos de aduana sobre productos agrícolas, alimentos procesados y bebidas, y se logran concesiones muy importantes en productos agrarios de carácter muy sensible para Japón, como carne de vacuno y cerdo, quesos y otros productos lácteos, malta y almidón.

Además, habrá contingentes para una serie de productos especiales: arancelarios para determinados quesos (frescos y procesados) y suero lácteo, y contingentes adicionales al ya existente en el marco OMC para leche desnatada en polvo, mantequilla y leche condensada. El sector del vino será especialmente beneficiado. A la eliminación de aranceles en dicho sector habrá que sumar otras ventajas no arancelarias para los empresarios españoles. Se reconocen 23 indicaciones geográficas $(\mathrm{IG})^{11}$ de vinos españoles y las prácticas enológicas habituales en la UE. Se aprueban más de veinte aditivos utilizados comúnmente por los productores comunitarios.

En el sector porcino, la reducción de aranceles afectará posiblemente a las exportaciones de productos como jamón o paleta curada.

10 Datos de la Comisión Europea, http://ec.europa.eu/trade/policy/infocus/eu-japan-economic-partnership-agreement/

11 Se reconocen las siguientes IG: Alicante, Bierzo, Cataluña, Cava, Empordá, Jeréz-Sherry, Jumilla, La Mancha, Málaga, Manzanilla-Sanlúcar de Barrameda, Navarra, Penedés, Priorat, Rías Baixas, Ribera del Duero, Rioja, Rueda, Somontano, Toro, Utiel-Requena, Valdepeñas y Valencia.

\subsection{Sector de productos industriales. Automoción}

Con respecto a los productos industriales, se liberaliza a la entrada en vigor el sector del automóvil, pasando a ser los aranceles del $0 \%$ (frente a los aranceles previos al acuerdo, que podían llegar a ser del 8,4\%). Del mismo modo, los aranceles pasan a ser del $0 \%$ a la entrada en vigor del acuerdo para los productos farmacéuticos (anteriormente de hasta un 5,3\%), maquinaria y los productos eléctricos (hasta un 4,8\%).

Cabe valorar de manera aceptable el resultado del acuerdo en lo que respecta a automoción, ya que ha constituido el primer y más destacable elemento ofensivo de la negociación para Japón. Se ha logrado mejorar el acceso al mercado japonés de los vehículos comunitarios con respecto a la situación que existía previamente. Por un lado, Japón elimina los aranceles que aplicaba a los automóviles comunitarios a la entrada en vigor del acuerdo el 1 de febrero de 2019. Dicha concesión se realiza de forma asimétrica, ya que los aranceles que impone la UE a los vehículos japoneses en la importación se eliminarán de forma progresiva en un periodo que oscila entre 3 y 12 años. Se ha logrado que Japón reconozca los estándares internacionales en automoción, al tiempo que se reduce el tipo impositivo en vehículos del segmento kei-cars. Por lo tanto, gracias al compromiso de Japón de alinear su normativa con las normas internacionales, la exportación de coches europeos a Japón se verá simplificada significativamente, con la consiguiente reducción de costes que ello supondrá.

Se ha podido introducir una cláusula de snap back ${ }^{12}$ para garantizar el cumplimiento de los compromisos establecidos por Japón. $\triangleright$

12 Esta cláusula permite eliminar las preferencias otorgadas por un socio al otro socio en caso de incumplimiento con respecto a los compromisos vinculados al anexo sectorial de automoción. 
Por otra parte, se aplican unas reglas de origen que fijan límites máximos de mercancías no originarias de Japón para poder exportar los vehículos japoneses. Estos límites son mayores con la entrada en vigor del acuerdo, pero van reduciéndose con el tiempo (en turismos, por ejemplo, el máximo porcentaje de mercancías no originarias es del $55 \%$, y se reduce hasta el $45 \%$ a los 7 años de la entrada en vigor del acuerdo).

Asimismo, las partes alinean sus estándares en el sector de los productos farmacéuticos, ampliándose el reconocimiento mutuo ${ }^{13} \mathrm{a}$ productos farmacéuticos biológicos, ingredientes activos y productos estériles, entre otros. Se armonizan también estándares en el sector de productos químicos (se adoptan las directrices del $\mathrm{ICH}^{14}$ ), de textil y calzado (estándares TBT de la OMC en materia de etiquetado, y también la norma ISO $3758^{15}$ ), de maquinaria y productos eléctricos (se reconocen estándares internacionales como los de ISO, entre otros) y de dispositivos médicos (se adopta la norma ISO 14155 como referente en materia de buenas prácticas clínicas).

\subsection{Propiedad intelectual}

Aunque tanto la UE como Japón disponen de sistemas robustos de protección de derechos de propiedad intelectual, el acuerdo mejora de manera importante dicha protección.

La firma del acuerdo conlleva un mayor reconocimiento a los derechos de autor. Además, se incorporan elementos para la protección de

\footnotetext{
13 En el Acuerdo de Reconocimiento Mutuo (ARM) de 2004 se incluían los fármacos de base química, radio-farmacéuticos, vitaminas y minerales.

14 International Council for Harmonization $(\mathrm{ICH}$, por sus siglas en inglés) of Technical Requirements for Pharmaceuticals for Human Use.

15 Norma ISO 3758: Textiles. Código para etiquetado de conservación por medio de símbolos.
}

los secretos comerciales, se obtiene una sustancial armonización de las normas japonesas en patentes y el reconocimiento de una remuneración equitativa por el uso de los derechos, entre otras cuestiones.

En virtud del acuerdo, Japón ha aceptado proteger más de doscientas indicaciones geográficas de la UE, afectando a muchas de las exportaciones de alimentos y bebidas a Japón. Esto significa que Japón protegerá los productos tradicionales europeos frente a las imitaciones, brindando el mismo nivel de protección que la UE.

En el caso de España, 42 indicaciones geográficas $^{16}$ han sido reconocidas y protegidas. Además, el acuerdo prevé que puedan incluirse nuevas indicaciones geográficas en el futuro, otorgándose el mismo el nivel de protección que en el caso de las ya reconocidas.

\subsection{Contratación pública}

El capítulo de «Contratación Pública» representa una de las grandes ventajas que el acuerdo brinda a las empresas de la UE. Con este acuerdo, Japón, que más allá de las respectivas obligaciones derivadas del Acuerdo Plurilateral de Compras Públicas (GPA) de la OMC tenía su mercado virtualmente cerrado a la competencia exterior, ha abierto su contratación pública a las empresas de la UE con la inclusión de nuevas disciplinas.

De este modo, las empresas de la UE podrán presentar ofertas para suministrar $D$

\footnotetext{
16 Aceite del Bajo Aragón, Antequera, Azafrán de La Mancha, Baena, Cítricos Valencianos, Guijuelo, Idiazábal, Jabugo, Jamón de Teruel, Jijona, Mahón-Menorca, Priego de Córdoba, Queso Manchego, Sierra de Cazorla, Sierra de Segura, Sierra Mágina, Siurana, Turrón de Alicante, Alicante, Bierzo, Brandy de Jerez, Cataluña, Cava, Empordá, Jerez/Xérèz/Sherry, Jumilla, La Mancha, Málaga, Manzanilla-Sanlúcar de Barrameda, Navarra, Pacharán Navarro, Penedés, Priorat, Rías Baixas, Ribera del Duero, Rioja, Rueda, Somontano, Toro, Utiel-Requena, Valdepeñas, Valencia.
} 
bienes y servicios a nivel central y subcentral (se abren a contratación pública para empresas comunitarias 54 core cities ${ }^{17}$ ) y también para empresas públicas (hospitales, universidades y de transporte). Esta mejora afecta también al sector del ferrocarril, ya que la eliminación de la denominada cláusula de seguridad operativa (OSC por sus siglas en inglés) supone la apertura de ese mercado por encima de un determinado umbral.

Además, Japón hará más transparente el proceso de licitación gracias a la publicación en inglés de los concursos públicos, en las páginas web correspondientes.

\subsection{Comercio y desarrollo sostenible}

El acuerdo incorpora los principales elementos clave del enfoque de la UE sobre comercio y desarrollo sostenible, y está en consonancia con otros acuerdos comerciales negociados y firmados por la UE, habiéndose logrado incluso mayores compromisos en algunas disciplinas sobre los acuerdos existentes. Es notable el hecho de que se trata del primer acuerdo negociado por la UE que recoge obligaciones específicas en relación con los compromisos adquiridos por los socios como firmantes del Acuerdo de París ${ }^{18}$. Las partes también se comprometen a la conservación y la gestión sostenible de recursos naturales y a la ratificación y el cumplimento de las convenciones fundamentales de la Organización Internacional del Trabajo $(\mathrm{OIT})^{19}$. La UE y Japón acuerdan promover la responsabilidad social corporativa,

\footnotetext{
17 Ciudades claves que cuentan con una población superior a 300.000 habitantes.

18 Acuerdo dentro del marco de la Convención Marco de las Naciones Unidas sobre el Cambio Climático.

19 Japón tiene pendiente la ratificación de las convenciones fundamentales de la OIT número 105 (eliminación de trabajo forzoso) y 111 (discriminación en el entorno laboral).
}

incluyéndose por primera vez en un acuerdo comercial un capítulo específico sobre gobernanza corporativa. Para blindar estos compromisos, la UE y Japón se comprometen a no disminuir las exigencias de la legislación nacional en materia laboral y medioambiental para atraer el comercio y las inversiones.

Con este acuerdo se promoverá además el comercio de productos sostenibles. Los compromisos establecidos en el capítulo podrán ser discutidos por las partes a través de un mecanismo de solución de diferencias EstadoEstado y se garantiza la participación de grupos de expertos, sociedad civil y organismos internacionales como la Organización Internacional del Trabajo en la resolución de las cuestiones del comercio, los derechos laborales y el medioambiente.

\subsection{Servicios e inversiones}

En cuanto a servicios, la UE exporta servicios a Japón por un valor aproximado de 28.000 millones de euros cada año ${ }^{20}$. El acuerdo facilitará a las empresas europeas la prestación de sus servicios en el mercado japonés. Así, las empresas europeas tendrán más oportunidades de prestar servicios en Japón y de mejorar el acceso a determinados sectores, especialmente en los casos de transporte marítimo, telecomunicaciones, transporte terrestre y aéreo, distribución, servicios a empresas y servicios financieros.

El acuerdo no afecta a los servicios públicos, por lo que las Administraciones de los Estados miembros de la UE podrán decidir mantener sus monopolios públicos y no se $\triangle$

20 Datos de la Comisión Europea, http://ec.europa.eu/trade/policy/infocus/eu-japan-economic-partnership-agreement/ 
verían obligadas a privatizar o liberalizar, por ejemplo, los relativos a la sanidad, la educación o el suministro de agua. Por lo tanto, los Estados miembros de la UE mantendrán derecho a regular, conservando la capacidad de decidir qué servicios serán universales y públicos.

Por otra parte, se mejora la movilidad temporal de los trabajadores, facilitando la internacionalización de las empresas comunitarias. Se han acordado seis categorías de trabajadores que pueden desplazarse ${ }^{21}$ (frente a las tres del GATS ${ }^{22}$ ) con un plazo de cinco años de estancia para todas las categorías de trabajadores de larga duración. Además, se permite acceso a cónyuges e hijos en todas las categorías de larga duración, permitiéndose al cónyuge el acceso al mercado laboral japonés.

Respecto a la inversión, el acuerdo tiene como objetivo fomentarla mediante medidas de liberalización. Se incluyen disposiciones sobre gobernanza corporativa, con el objetivo de atraer y fomentar la inversión mediante el aumento de la confianza del inversor. En materia de protección de inversiones, la UE y Japón continúan sus negociaciones, con el objetivo de poder firmar un acuerdo en este sentido en el futuro.

\subsection{Pequeñas y medianas empresas}

Finalmente, el Acuerdo UE-Japón es el primero en incorporar un capítulo específico relativo a las pymes, reconociendo su importancia en el comercio entre ambas partes. Este capítulo permitirá a las pequeñas y medianas empresas beneficiarse plenamente del acuerdo gracias a una mayor transparencia.

\footnotetext{
21 Traslados intraempresariales (ICT), inversores, proveedores de servicios contractuales (CSS), profesionales independientes (IP), personas en visita de negocios con fines de establecimiento (BVEP) y personas en visita de negocios de corta duración (STBV).

22 Acuerdo General de Comercio de Servicios de la OMC.
}

La UE y Japón se comprometen a crear un sitio web específico para facilitar a las pequeñas empresas información relevante y adecuada relativa al acceso al mercado en el marco del acuerdo. Se crearán asimismo puntos de contacto específicos para las pequeñas y medianas empresas con objeto de gestionar las cuestiones planteadas en este capítulo, además de poder tratar cuestiones que preocupen a las empresas en otros ámbitos del acuerdo.

\section{Conclusión}

Con la firma del Acuerdo de Partenariado Económico, la UE y Japón, dos de las economías más grandes del mundo, lanzan un mensaje claro de rechazo al proteccionismo imperante actualmente en la escena internacional.

Se trata de un acuerdo muy ambicioso, amplio y profundo con una casi plena liberalización de aranceles y desmantelamiento de barreras no arancelarias, que beneficiará especialmente a sectores exportadores de la UE tan diversos como el agroalimentario, el textil, el del calzado, la automoción, la maquinaria o el de servicios. Se logra así el acceso a un mercado con unos estándares muy exigentes y que tradicionalmente ha estado cerrado a las exportaciones de la UE. El acuerdo incorpora la mayor parte de las cuestiones clave para la UE y para España, como el comercio sostenible e inclusivo, la protección al consumidor, el acceso a la contratación pública o los derechos de la propiedad intelectual.

Para maximizar los beneficios de este acuerdo, es muy importante que las empresas lo conozcan y lo apliquen. Por esta razón, la Secretaría de Estado de Comercio está realizando una campaña de divulgación del mismo, con diversas conferencias y jornadas en $\triangleright$ 
distintos puntos de España ${ }^{23}$, así como material online que se puede consultar en la página de la Secretaría de Estado de Comercio ${ }^{24}$. Cabe destacar que, en septiembre de 2019, está previsto un evento de presentación del acuerdo organizado por la Secretaría de Estado de Comercio, ICEX, CEOE y la Cámara de Comercio de España, donde se contará además con la colaboración de la Embajada de Japón en España. En este evento se presentarán las oportunidades que ofrece el acuerdo con Japón a través de diversas mesas sectoriales, que contarán con la participación de empresas y representantes de la Secretaría de Estado de Comercio.

Asimismo, es muy importante que los exportadores se registren en el sistema REX para poder aprovechar las preferencias que ofrece el acuerdo.

Además, la UE y España siguen con máximo interés la evolución de la implantación y la maximización de los beneficios del acuerdo. En este sentido, será muy importante que en esta etapa se avance en la resolución de las barreras pendientes.

23 Se han celebrado jornadas, entre otras, en Avilés, Barcelona Bilbao, Ferrol, Madrid, Málaga, Murcia Pamplona, La Rioja, Valencia, Valladolid, Vigo y Zaragoza.

24 http://www.comercio.gob.es/es-ES/comercio-exterior/politicacomercial/relaciones-bilaterales-union-europea/asia/Documents/ Ficha\%20Japón.pdf

\section{Páginas web}

Folleto informativo de la SEC sobre el Acuerdo con Japón y fichas sectoriales. Recuperado de http:// www.comercio.gob.es/es-ES/comercio-exterior/ politica-comercial/relaciones-bilaterales-unioneuropea/asia/Documents/Ficha\%20Japón.pdf

Página web de la SEC referida al Acuerdo con Japón. Recuperado de http://www.comercio.gob. es/es-ES/comercio-exterior/politica-comercial/ relaciones-bilaterales-union-europea/asia/ Paginas/japon.aspx

Página web de la Comisión Europea sobre el Acuerdo. Recuperado de http://ec.europa.eu/trade/policy/in-focus/eu-japan-economic-partnershipagreement/

Portal de barreras en mercados exteriores: fichas de barreras de Japón. Recuperado de http:// www.barrerascomerciales.es/es-es/paises/ Paginas/pais.aspx?pais=Japón

Información de la Market Access Data Base (MADB) de la Comisión Europea sobre Japón. Recuperado de https://madb.europa.eu/madb/fta_japan _overview.htm

Información de ICEX España Exportación e Inversiones sobre Japón. Recuperado de https://www. icex.es/icex/es/navegacion-principal/todosnuestros-servicios/informacion-de-mercados/ paises/navegacion-principal/el-pais/informacion-economica-y-comercial/index.html? idPais $=J P$ 


\section{ANEXO 1}

\section{DATOS DE COMERCIO BILATERAL ESPAÑA-JAPÓN}

DESGLOSE SECTORIAL (EXPORTACIONES)

(En millones de euros)

\begin{tabular}{|c|c|c|c|c|c|c|c|}
\hline & 2016 & $\%$ del total & 2017 & $\%$ del total & 2018 & $\%$ del total & $\begin{array}{c}\text { Variación } \\
17 / 18\end{array}$ \\
\hline 1. Alimentación, bebidas y tabaco & 739,2 & 30,7 & 858,2 & 35,1 & 883,4 & 35,0 & 3,04 \\
\hline 2. Productos energéticos & 6,3 & 0,3 & 0,9 & 0,04 & 1,2 & 0,05 & 36,2 \\
\hline 3. Materias primas & 181,8 & 7,6 & 135,9 & 5,6 & 170,2 & 6,7 & 26,3 \\
\hline 4. Semimanufacturas & 603,8 & 25,1 & 580,0 & 23,7 & 628,2 & 24,8 & 8,2 \\
\hline 5. Bienes de equipo & 174,6 & 7,3 & 185,8 & 7,6 & 182,2 & 7,2 & $-1,7$ \\
\hline 6. Sector del automóvil & 404,7 & 16,8 & 364,9 & 14,9 & 332,2 & 13,1 & $-8,9$ \\
\hline 7. Bienes de consumo duradero & 11,2 & 0,5 & 15,1 & 0,6 & 10,5 & 0,4 & $-30,1$ \\
\hline 8. Manufacturas de consumo & 278,6 & 11,6 & 298,8 & 12,2 & 303,1 & 11,9 & 1,5 \\
\hline 9. Otras mercancías & 5,4 & 0,2 & 6,7 & 0,3 & 15,8 & 0,6 & 136,3 \\
\hline Total & $2.405,7$ & 100,0 & $2.446,6$ & 100,0 & $2.527,5$ & 100,0 & 0,03 \\
\hline
\end{tabular}

DESGLOSE SECTORIAL (IMPORTACIONES)

(En millones de euros)

\begin{tabular}{|l|r|r|r|r|r|r|r|}
\hline & $\mathbf{2 0 1 6}$ & \% del total & $\mathbf{2 0 1 7}$ & \% del total & $\mathbf{2 0 1 8}$ & \% del total & $\begin{array}{c}\text { Variación } \\
\mathbf{1 7 / 1 8}\end{array}$ \\
\hline 1. Alimentación, bebidas y tabaco & 12,4 & 0,3 & 13,8 & 0,4 & 12,6 & 0,3 & $-8,9$ \\
2. Productos energéticos & 16,2 & 0,4 & 12,8 & 0,3 & 40,9 & 1,0 & 226,9 \\
3. Materias primas & 15,3 & 0,4 & 17,8 & 0,5 & 19,0 & 0,5 & 7,6 \\
4. Semimanufacturas & 418,1 & 11,5 & 394,0 & 10,0 & 431,8 & 10,5 & 9,7 \\
5. Bienes de equipo & $1.277,0$ & 35,1 & $1.334,9$ & 33,9 & $1.371,6$ & 33,2 & 2,3 \\
6. Sector del automóvil & $1.786,9$ & 49,1 & $2.048,9$ & 52,1 & $2.136,2$ & 51,7 & 4,2 \\
7. Bienes de consumo duradero & 0,4 & 0,5 & 20,4 & 0,5 & 21,0 & 0,5 & 3,0 \\
8. Manufacturas de consumo & 2,6 & 2,5 & 83,4 & 2,1 & 94,4 & 2,3 & 13,0 \\
9. Otras mercancías & 0,1 & 0,0 & 2,0 & 0,1 & 4,1 & 0,1 & 101,8 \\
\hline Total & $\mathbf{3 . 6 9 3 , 3}$ & $\mathbf{1 0 0 , 0}$ & $\mathbf{3 . 9 2 8 , 3}$ & $\mathbf{1 0 0 , 0}$ & $\mathbf{4 . 1 3 2 , 1}$ & $\mathbf{1 0 0 , 0}$ & $\mathbf{5 , 0}$ \\
\hline
\end{tabular}

